\title{
Alkaptonuria diagnosed in a one year old boy: a case report
}

\author{
*H W Dilanthi ${ }^{1}$, G A M Kularatnam ${ }^{1}$, S Jayasena ${ }^{1}$, E A Jasinge ${ }^{1}$, K S H de Silva ${ }^{2}$
}

Sri Lanka Journal of Child Health, 2016; 45(4): 291-293

DOI: http://dx.doi.org/10.4038/sljch.v45i4.8037

(Key words: Alkaptonuria, homogentisic acid, homogentisic acid oxidase)

\section{Introduction}

Alkaptonuria is an autosomal recessive disorder with an estimated incidence of 1 in 250,000 to 1 million live births ${ }^{1}$. Due to a deficiency of the enzyme homogentisic acid oxidase (HGO), homogentisic acid (HGA) cannot be further metabolized and results in accumulation of HGA and its oxidative metabolites in blood, connective tissue and urine, causing a triad of homogentisic aciduria, ochronosis and arthritis ${ }^{1,2}$. We report a case which was biochemically confirmed by quantifying HGA in urine.

\section{Case report}

A one-year-old male infant born at term, presented with blackish discolouration of napkins moistened with urine when left unwashed for many hours. The intensity of the stain had increased while washing with soap. His mother had noticed this since birth for which she had sought medical advice. Initially child had been investigated for urinary tract infections and mother had been reassured. At presentation to Lady Ridgeway Hospital at one year of age he was thriving and developing normally and physical examination revealed no abnormality. $\mathrm{He}$ is the third child of nonconsanguineous healthy parents and his siblings aged three and six years are also healthy. The urine appeared normal on collection but it turned dark brown to black on prolonged exposure to the atmosphere. The urine $\mathrm{pH}$ was 5.5 and other routine laboratory investigations were normal. When urine was heated with Benedict reagent a dark supernatant and a yellow precipitate of cuprous oxide was formed which suggested the presence of HGA (Figure 1).

\footnotetext{
${ }^{1}$ Department of Chemical Pathology, Lady Ridgeway Hospital for Children, Colombo, Sri Lanka; ${ }^{2}$ Department of Paediatrics, Faculty of Medicine, University of Colombo, Sri Lanka
}

*Correspondence: dilanthiw@gmail.com.

(Received on 25 November 2015: Accepted after revision on 21 January 2016)

The authors declare that there are no conflicts of interest Personal funding was used for the project.

Open Access Article published under the Creative

Commons Attribution CC-BY CC License.

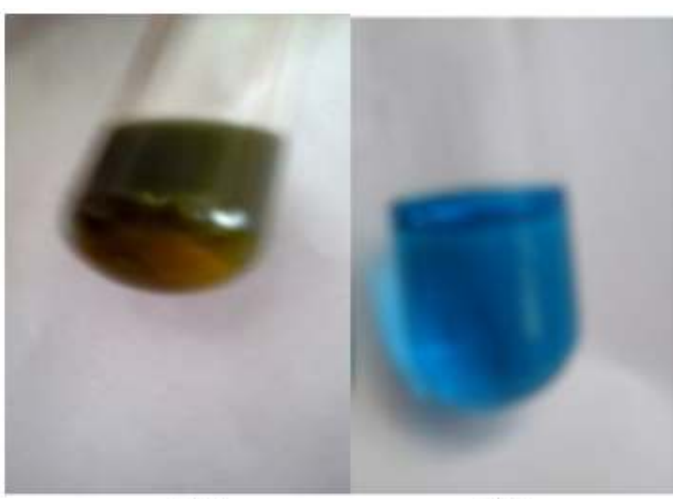

(a)

(b)

Figure 1: Benedict test for urine homogentisic acid: (a) Dark supernatant \& a yellow precipitate (b) Negative control

Addition of ammoniacal silver nitrate to urine immediately produced a black precipitate indicating the presence of HGA (Figure 2).

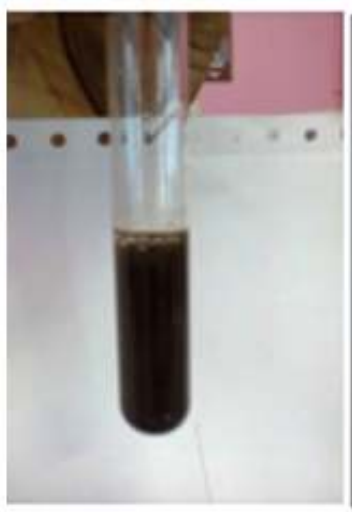

(a)

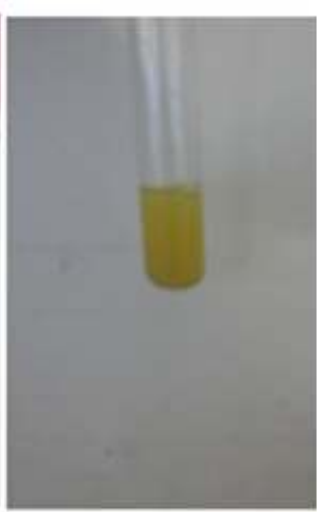

(b)
Figure 2: Ammoniacal silver nitrate test (a) Development of greenish black colour (b) Negative control

These basic qualitative tests supported the clinical suspicion of alkaptonuria. Semi quantitative analysis of urine by gas chromatography / mass spectrometry performed in a reference laboratory in India revealed elevated levels of HGA. The relative peak area of the compound with respect to internal standard was $1561.69 \%(0.00 \%-1.40 \%)$. This helped to confirm the diagnosis of alkaptonuria. 

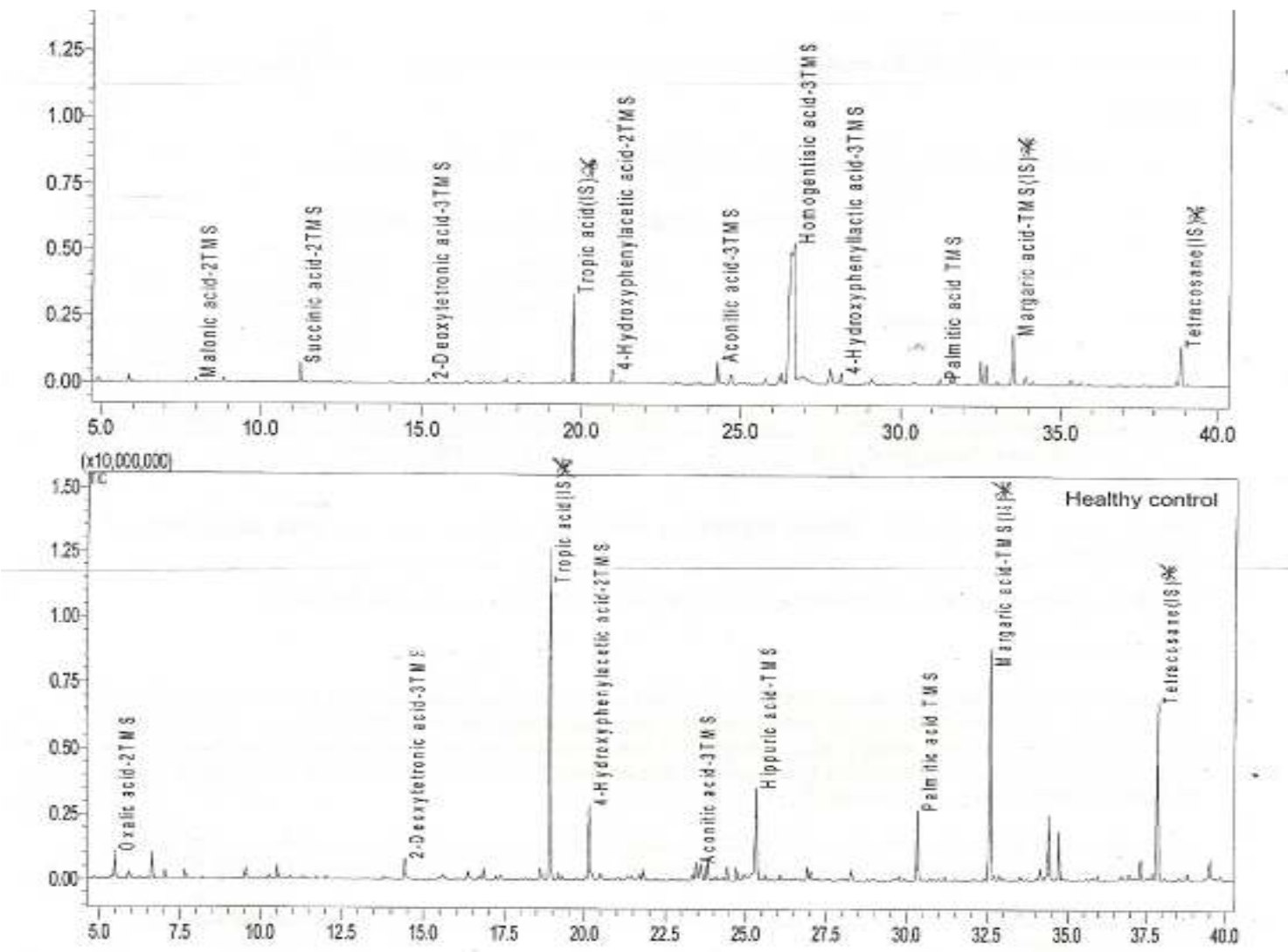

※ IS-Intemal Standard

Figure 3: Urine organic acid profile - Chromatogram showing significant elevation of HGA

He was treated with ascorbic acid and a low protein diet was recommended. He was advised to have regular follow up.

\section{Discussion}

The urine of the patients with alkaptonuria darkens on standing, due to oxidation and polymerization of HGA to a melanin like product ${ }^{1,2}$. Polymerization is enhanced by alkali, which explains the increase in intensity of the stain when diapers were washed with soap ${ }^{2}$. In alkaptonuric patients fresh urine does not have an abnormal colour and may not darken for many hours if it remains at an acid $\mathrm{pH}^{2}$. As a result, in alkaptonuric patients this finding may be overlooked. During childhood alkaptonuria may be asymptomatic and during adulthood they may present with blackish pigmentation of connective tissues namely sclera and cartilage of the ears ${ }^{2,3}$.

Alkaptonuric patients may develop complications due to multiorgan involvement associated with rupture of tendons and ligaments, prostatitis, renal stones, generalized arteriosclerosis and calcification in the heart valves leading to myocardial infarction ${ }^{1,2}$. Although alkaptonuria causes morbidity in these patients, they have a normal life $\operatorname{span}^{3}$. Diagnosis of alkaptonuria requires detection of elevated levels of HGA in urine $^{2}$. Oxidation property of HGA reduces the copper reagent in Benedict solution yielding a yellow orange precipitate with a dark supernatant ${ }^{2}$. The addition of silver nitrate and ammonium hydroxide to urine also produces a black colour ${ }^{4}$. Quantitative determination of urinary HGA can be done by gas chromatography-mass spectrometry ${ }^{1,2}$. In our patient, it revealed a significantly high urinary excretion of HGA.

Treatment of alkaptonuria is based on restricting the intake of tyrosine and phenylalanine containing proteins and preventing the oxidation of HGA by the early use of reducing agents such as ascorbic $\operatorname{acid}^{2,5}$. Eva et al (2003) reports that the improvement in clinical symptoms and reversal of radiological evidence of joint involvement with these treatment strategies are possible ${ }^{5}$. However, protein restriction in young infants is difficult as their growth will be restricted. There is no definitive treatment for these patients. Regular long-term follow-up is needed to monitor growth and complications. 
Since alkaptonuria is a rare disease and may be asymptomatic in childhood, a high degree of clinical suspicion and awareness is essential for early detection of the disease. In our patient though the mother had noticed blackish discoloration of urine since birth, diagnosis was delayed as he had been investigated for urinary tract infections. Urinary qualitative tests which can be performed in any clinical laboratory are useful to support the clinical diagnosis in the absence of chromatographic confirmation.

\section{Acknowledgements}

We acknowledge the medical laboratory technologists in the Department of Chemical Pathology, Lady Ridgeway Hospital for Children, Sri Lanka for their support in biochemical investigations.

\section{References}

1. Phornphutkul C, Introne WJ, Perry MB, Bernardini I, Murphey MD, Fitzpatrick DL, et al. Natural history of alkaptonuria. New England Journal of Medicine 2002; 347(26): 2111-21.

http://dx.doi.org/10.1056/NEJMoa021736

PMid: 12501223
2. La Du BN. Alkaptonuria. In: Scriver CR, Beaudet AL, Sly WS, et al. The Metabolic and Molecular Bases of Inherited Disease. New York: Mcgraw-Hill; 2001: p. 210923.

http://dx.doi.org/10.1006/rwgn.2001.0025

3. Rezvani I. Defects in Metabolism of Amino Acids. In: Kliegman RM, Behrman RE, Jenson HB, Stanton BF. Nelson Text Book of Paediatrics. USA: Elsvier, Saunders Co.; 2007: p. 529-66.

4. Strasinger SK, Di Lorenzo MS. Urine screening for metabolic disorders. In: Strasinger SK, Di Lorenzo MS. Urine analysis and body fluids. USA; 2001. p. 135-48.

5. Eva M, György K, Udo FHE, Ron AW. Reversal of clinical symptoms and radiographic abnormalities with protein restriction and ascorbic acid in alkaptonuria. Annals of Clinical Biochemistry 2003; 40: 108-11. http://dx.doi.org/10.1258/0004563033210 16268

PMid: 12542920 